\title{
Shortcut nitrification-denitrification can be attributed to the operation pattern of intermittent aeration profile
}

\author{
C.D. GAO ${ }^{1}$ \& S.S. FAN ${ }^{1}$, E.L. JIAO ${ }^{1}$, Y. TIAN ${ }^{1}$, R.F. $\mathrm{LI}^{1}$ \\ ${ }^{1}$ Key Laboratory of Beijing for Water Quality Science and Water Environmental Recovery \\ Engineering, Beijing University of Technology, Beijing 100022, China
}

KEYWORD: Intermittent aeration profile; shortcut nitrification-denitrification; SBR; predenitrification

ABSTRACT: In this study, two lab-scale reactors were set up and operated in this study, include a sequencing batch reactor for batch tests and a continuous predenitrification bioreactor for regular operation. Batch tests fed by Synthetic wastewater (acetate) and operated in intermittent aeration profile, demonstrate that the alternating anoxic/aerobic condition can inhibit NOB and induce nitrite accumulation from vary first time, though the sludge is collected from a complete nitrificationdenitrification process. Intermittent aeration profile applied on a continuous predenitrification reactor treating low-strengthen municipal wastewater and realized partial shortcut nitrification-denitrification without changing any other operation parameters, which increased $\mathrm{TN}$ removal rate from average $60 \%$ to $70 \%$ without add extra carbon resources.

\section{INTRODUCTION}

\section{Shortcut nitrification-denitrification}

Biological nitrogen removal (BNR) process has been most commonly used in Waste Water treatment plants. With the more Rigorous treatment requirement imposed in most country, the process demand more energy. As a consequence, shortcut nitrification-denitrification, remove nitrogen via nitrite pathway, was developed and became a hot point in the field of wastewater treatment [1]. Compared with the traditional biological nitrogen removal process, shortcut nitrification-denitrification process could save $25 \%$ of the amount of oxygen, $40 \%$ of denitrification carbon source, and decrease $30 \%$ of biomass production in anoxic phase [2]. There are several methods such as high temperature, high $\mathrm{pH}$ values, high free ammonia concentration, low dissolved oxygen and intermittent aeration profile (IAP) have been proved to be and effective methods to inhibit nitrite-oxidizing bacteria (NOB) growth, thus achieving shortcut nitrification-denitrification.

\section{Intermittent aeration profile}

The intermittent aeration profile describes the air feeding strategy of an activated sludge reactor and include several pairs of oxic phase and aerobic phase. Previous studies have proved that intermittent aeration can inhibited NOB by anoxic disturbance while not affect AOB in sequencing batch reactors (SBRs) [3]. The proved method can be easily controlled and does not require adding chemicals compare to other approaches. However, there are few studies about shortcut nitrification-denitrification achieved by intermittent aeration profile in continuous BNR [4].

\section{MATERIALS AND METHODS}

\section{Experimental devices and operation conditions}

Two lab-scale reactors were set up and operated in this study, include a sequencing batch reactor for batch tests and a continuous predenitrification bioreactor for regular operation. Both reactors were seeded with return activated sludge from the secondary settling tank of Gaobeidian WWTP, operated in AO process.

The SBR reactor (figure 1) with an active volume of 8L, fed by Synthetic wastewater (acetate) and was operated in intermittent aeration profile, in the sequence of fill $(10 \mathrm{~min})$, anoxic phase $(20 \mathrm{~min})$ 
and aerobic phase (20min), which repeated for 8 times, final anoxic phase $(20 \mathrm{~min})$, settle (90 min), idle (5 $\mathrm{min})$ phase

The continuous predenitrification bioreactor was operated as two-step predenitrification process with a working volume of $55 \mathrm{~L}$ and consisted of two corridors and each corridor was separated to 5 chambers

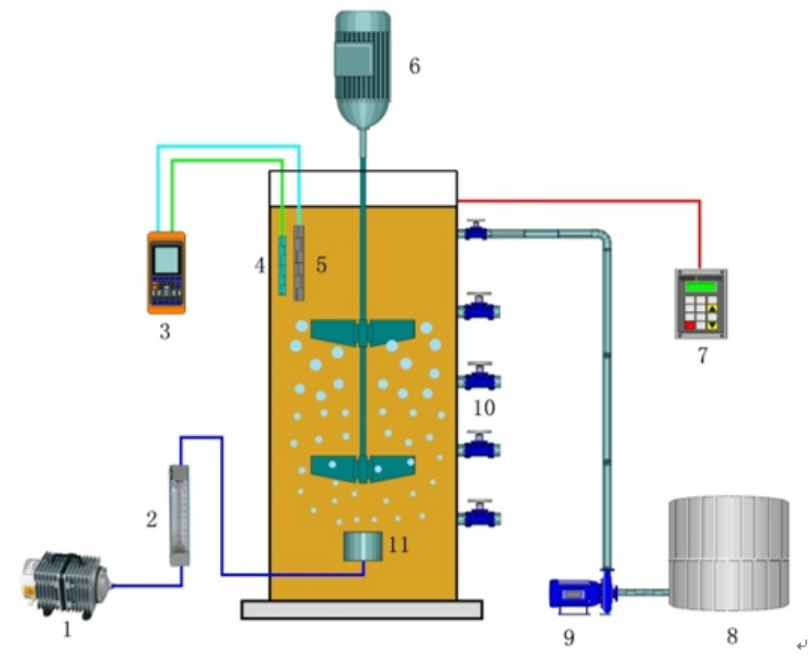

Figure 1. Schematic representation of the SBR in this study: 1- air Compressor; 2- air flow meter; 3DO meter; 4-PH probe; 5-DO probe; 6- electric mixer; 7- temperature Controller; 8- sewage tank; 9sewage pumps; 10- effluent outlet; 11-air diffuser stone

( 2 anoxic and 3 aerobic). The raw water from influent tank was pumped into anoxic zone, then flowed through aerobic zone, the second anoxic zone, the second aerobic zone successively. The effluent was partially pumped back to first anoxic zone to accomplish denitrification, which had an internal reflux ratio of $400 \%$, and partially flowed into the cylindrical clarifier. Stirrers was established in each chamber to maintain the liquid mixed completely and sand diffusers was placed in each aerobic zone to flush compressed air, shown in fig. 2 .

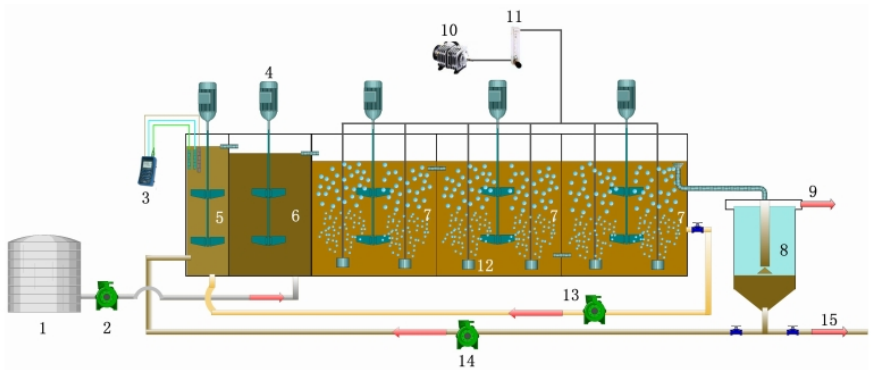

Figure 2. Schematic representation of the continuous bioreactor in this study: 1- influent tank; 2- influent pump; 3-DO meter; 4-stirer ; 5-preanoxic zone; 6- anoxic zone; 7- aerobic zone; 8- clarifier; 9outlet; 10- air Compressor; 11- gas flow meter 12-air diffuser stone; 13- internal reflux; 14- return sludge; 15- excess sludge.

\section{Wastewater characterization}

The main characteristics of the Synthetic wastewater used in batch test are described as follows, COD (acetate): $300 \pm 10 \mathrm{mg} / \mathrm{L} ; \mathrm{NH}_{4}{ }^{+}-\mathrm{N}-\mathrm{N}: 70 \pm 2.2 \mathrm{mg} / \mathrm{L} ; \mathrm{pH}: 7.5 \pm 0.1$.

The raw water in the influent tank was collected from a sewer of residential area, and the specific characteristics are described as follows, COD: $160-320 \mathrm{mg} / \mathrm{L} ; \mathrm{NH}_{4}{ }^{+}-\mathrm{N}: 40-80 \mathrm{mg} / \mathrm{L} ; \mathrm{NO}_{2}{ }^{-}-\mathrm{N}: 0.04-$ $0.26 \mathrm{mg} / \mathrm{L} ; \mathrm{NO}_{3}{ }^{-}-\mathrm{N}: 0.12-1.08 \mathrm{mg} / \mathrm{L} ; \mathrm{pH}: 7.0-7.8$ 


\section{Analysis methods.}

Ammonia, nitrate, nitrite, total nitrogen (TN), COD, mixed liquor suspended solids (MLSS) were measured according to the Standard Methods for the Examination of Water and Wastewater (APHA, 1998) [5].

\section{RESULTS AND DISCUSSION}

\section{Performance of batch tests}

In order to investigate the influence of intermittent aeration profile on the realization of shortcut nitrification-denitrification, two batches of experiment were conducted. The SBR reactor seeded with non- shortcut nitrification-denitrification sludge was operated in intermittent aeration profile, at different DO concentration, $1 \mathrm{mg} / \mathrm{L}$ and $2 \mathrm{mg} / \mathrm{L}$ respectively. As a result, accumulation of nitrite produced during the process, and the nitrite accumulation ratio (NAR) reached 50\% (fig.3), which mean intermittent aeration profile could inhabit NOB and shorten the nitrification-denitrification pathway from the very first time.
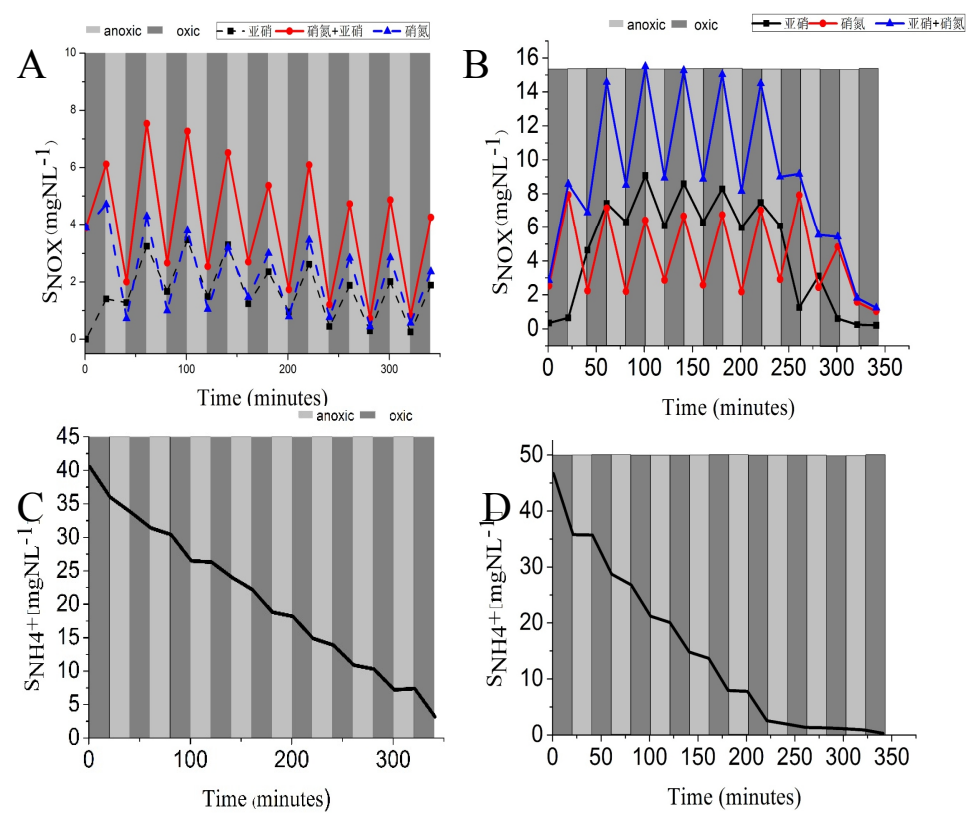

Figure 3. Typical phase about nitrification-denitrification under intermittent aeration profile in batch test: (A) NOX at DO=1mg/L, (B) NH4+-N -N at DO=1mg/L, (C) NOX at DO=2mg/L, (D) NH4+$\mathrm{N}-\mathrm{N}$ at $\mathrm{DO}=2 \mathrm{mg} / \mathrm{L}$.

To evaluate the effect of DO concentration on nitrite accumulation, a regular DO concentration $(2 \mathrm{mg} / \mathrm{L})$ and a low DO concentration $(1 \mathrm{mg} / \mathrm{L})$ were conducted. The experimental result by compared each DO concentration shows that at low DO concentration NAR value was more stable and fluctuation range of nitrite value was larger which indicated that nitrite was engaged more in denitrification. So that if the NAR is more than $50 \%$ and nitrite value decreases in anoxic phase, $20 \%$ denitrification carbon source will be saved and $15 \%$ biomass production will be avoided.

The obtained experimental results also proved that shortcut nitrification-denitrification can attributed to the operation pattern of intermittent aeration profile in SBRs.

\section{Performance of continuous predenitrification bioreactor}

To evaluate the feasibility of the realization of shortcut nitrification-denitrification in a continuous reactor, predenitrification process was chose to conduct the experiment, since which was most 
commonly used in municipal WWTPs. In this study, a two-step predenitrification bioreactor was set up with a loading rate of $220 \mathrm{~L} / \mathrm{d}$, DO value of $2 \sim 3 \mathrm{mg} / \mathrm{L}$ and MLSS of $3 \sim 4 \mathrm{~g} / 1$ and SRT of $30 \mathrm{~d}$. To actualize the intermittent aeration profile, internal reflux ratio was increased from $100 \%$ in stage 1 to $400 \%$ in stage 2 , which made the mix liquid frequently enough switched between aerobic and anoxic conditions, namely, 8 times' switches in the internal reflux ratio of $400 \%$.
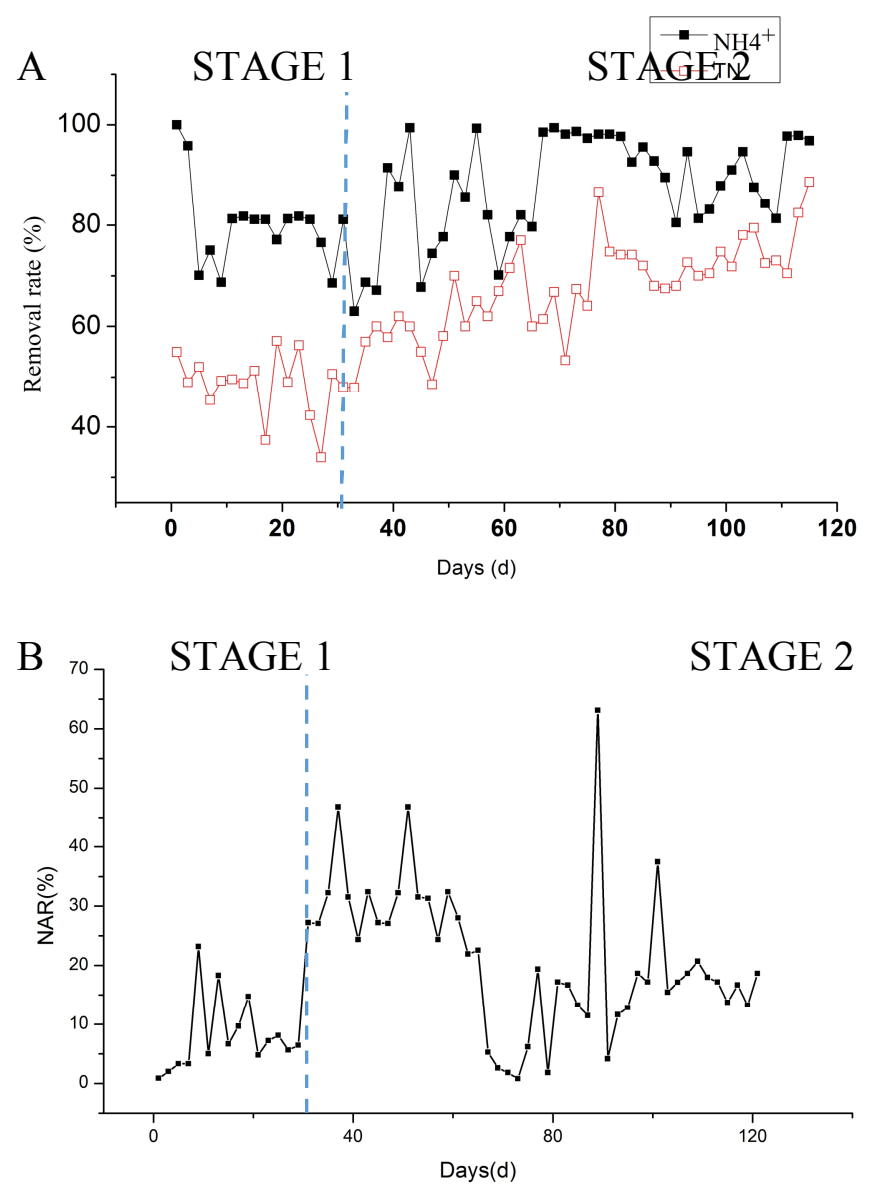

Figure 4 Performance of reactor: (A) TN and ammonia removal rate, (B) NAR.

As shown in figure 4, in start-up stage 1, TN and ammonia removal rate was lower than $80 \%$ and $60 \%$ respectively on most days. However, the Nitrite accumulation phenomenon appeared after 10 days' operation with the NAR of approximate $10 \%$. In stage 2, internal reflux ratio was increased to $400 \%$. As expected, NAR increased to average $35 \%$ at first, but then dropped to average $20 \%$. That might because the regular DO concentration's promotion and IAP's inhibition to NOB made NOB and AOB achieve balance[6]. However, the realization of partial shortcut nitrification-denitrification increased TN removal rate from average $60 \%$ to $70 \%$, which was a significant improvement for waste water treatment.

\section{CONCLUSION}

In this study, intermittent aeration profile was demonstrated as a feasible way to realize shortcut nitrification-denitrification both in sequencing batch reactors and continuous predenitrification. In addition, the effect of internal reflux ratio on NAR was analyzed. It is worthy to mention that the influent wastewater was low-strengthen municipal wastewater, and the realization of shortcut nitrification-denitrification could partially solute carbon resource deficit, which shows that AO 
process has the potential being a process to make the effluence match the high requirement of the new discharge standard. The conclusions were made as follows,

The batch test demonstrate that the alternating anoxic/aerobic condition can inhibit NOB and induce nitrite accumulation from vary first time, though the sludge is collected from a complete nitrification-denitrification process.

The application of IAP on a continuous predenitrification reactor can realize partial shortcut nitrification-denitrification without changing any other operation parameters.

Partial shortcut nitrification-denitrification in a high internal reflux ratio AO reactor increased TN removal rate from average $60 \%$ to $70 \%$.

In view of the NOB inhibition during anoxic disturbance, it is recommended to maintain an enough anoxic span and alternating times, more than 4 times.

\section{REFERENCES}

[1] Turk O, Mavinic D S. Water Research, 1989, 23(11): 1383-1388.

[2] Peng Y, Zhu G. Applied microbiology and biotechnology, 2006, 73(1): 15-26.

[3] Gao C D, Fan S X, Jiao E L, et al. Operation and Optimization of an Alternating Oxic-Anoxic Shortcut Nitrification-Denitrification System[J]. Advanced Materials Research, 2014, 10301032:387-390.

[4] G. Chun-Di, J. Er-Long, H. Kun, W. Li, L. Hao, Proceedings of the 2013 Third International Conference on Intelligent System Design and Engineering Applications, IEEE Computer Society, 2013, p. 1408

[5] American Public Health Association. APHA. 1998[J]. Standard methods for the examination of water and wastewater, 1998, 20.

[6] C.D. Gao, E.L. Jiao, H. Li, W.X. Wang, S.Y. Wang, Fresen Environ Bull, 22 (2013) 3607.

References in the text: Figure 1, Figures 2-4, 6, 8a, b (not abbreviated) 